\title{
Acute Radial Nerve Palsy Due to the Puncture Trauma of the Arm: A Case Report
}

Ghannam Abdelaziz ${ }^{1 *}$, Fekhaoui Mohammed Reda ${ }^{1}$, Moncef Boufettal ${ }^{2}$, Bassir Reda Allah ${ }^{2}$, Kharmaz Mohammed ${ }^{2}$, Lamrani Moulay $\mathrm{Omar}^{2}$, Berrada Mohammed Saleh ${ }^{2}$

${ }^{1}$ M.D, ${ }^{2} \mathrm{Ph} . \mathrm{D}$, Department of Trauma and Orthopaedic Surgery, Ibn Sina University Hospital, Rabat, Morocco

DOI: $10.36347 /$ sjams.2020.v08i09.002

| Received: 17.08.2020 | Accepted: 24.08.2020 | Published: 04.09.2020

*Corresponding author: Ghannam Abdelaziz

Abstract

Traumatic injury to peripheral nerves are common. In the upper limb, the radial nerve is the most commonly injured, followed by the ulnar and median nerves. The advent of microsurgery has revolutionized the management of these lesions, unfortunately functional outcomes remain mediocre. We report an atypical case of a 32-year-old man with a puncture wound of the left arm caused by a glass injury. Surgical exploration found a total section of the radial nerve repaired by direct suturing. Radial nerve injury may be due to physical open or closed trauma, infection or a tumoral compression. It's exceptionally during penetrating wounds because of his deep location. All Radial nerve palsies associated with open wounds should be explored surgically and primary nerve repair provides excellent results ranging between 78 and 90 percent. Initial clinical evaluation is important and all penetrating trauma need a surgical exploration: a puncture wound can be enough to damage a nerve, tendon, artery.

Keywords: Wound, peripheral nerve, radial palsy.

Copyright @ 2020: This is an open-access article distributed under the terms of the Creative Commons Attribution license which permits unrestricted use, distribution, and reproduction in any medium for non-commercial use (NonCommercial, or CC-BY-NC) provided the original author and source are credited.

\section{INTRODUCTION}

In Morocco, drug trafficking and drug-use has exploded. It become a significant threat to public safety increasing road traffic accidents and physical assault. Our institute provides comprehensive patient care in all aspects of traumatic and degenerative disorders of the adult and supports these patients. We report an atypical case of a 32-year-old patient with a puncture wound of the left arm caused by a glass injury. Surgical exploration found a total section of the radial nerve repaired by direct suturing. This work has been reported in line with the SCARE criteria [1].

\section{Case Presentation}

A 32-year-old, right-handed, man with no particular history was referred to our institute two-hours after physical assault. Physical examination found a stab wound of the lateral side of the left arm measuring
$1.5 \mathrm{~cm}$ with radial nerve palsy (Figure-1). Upper limb radiography was normal (Figure-2). Orthopedic team admitted the patient to the operating room. We explained to him the consequences of this trauma and the purpose of the surgical treatment. He was placed in a supine position with the left upper limb on a support. Then, surgical exploration was performed under general anesthesia and found a total section of the radial nerve (Figure-3) wich we repaired by epiperineural nerve sutures using a non-absorbable 8-0 sutures. An orthosis was applied to prevent vicious attitude. Electrical stimulations and passive exercises session was prescribe to keep a good muscular trophicity and prevent stifness. Follow-up assessement of muscle tone, strength of contraction and sensitivity will be rated according to the Medical Research Council (MRC) criteria. Electromyography will be done after six months. Unfortunately, the patient didn't consult, and we could't follow the evolution. 


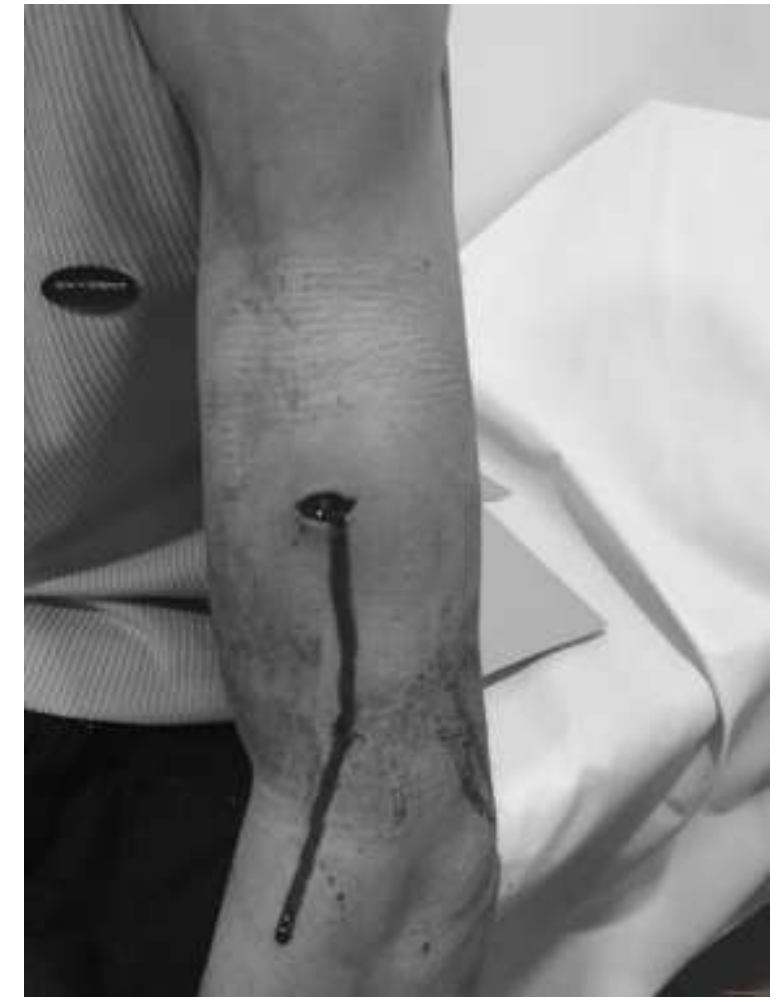

Fig-1: Clinical image showing the stab wound of the lateral side of the left arm

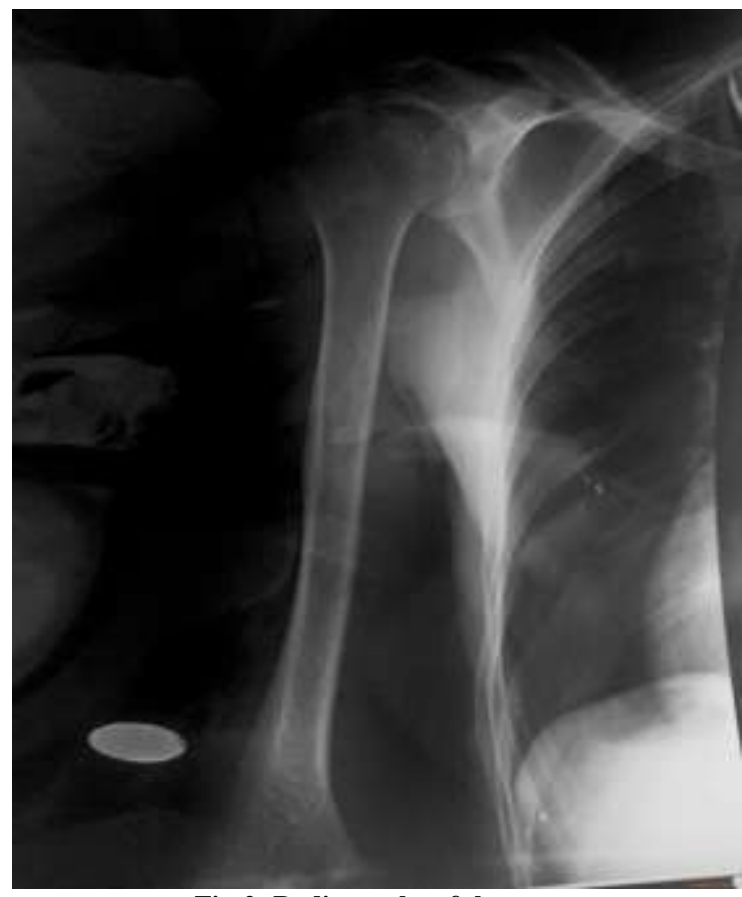

Fig-2: Radiography of the arm

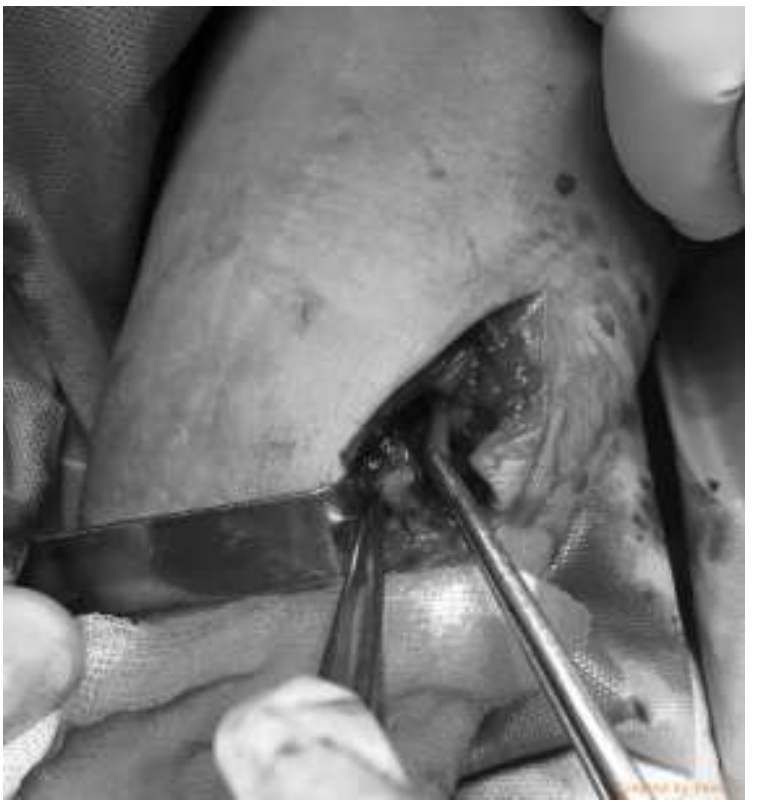

Fig-3: Intra-operative image showing total section of the radial nerve

\section{DisCUSSION}

Radial nerve injury may be due to physical open or closed trauma, infection or a tumoral compression. Fractures from the middle to the distal third of humerus most common for causing radial nerve palsy. The lesion of radial nerve is exceptionally during penetrating wounds because of his deep location [2-5]. It causes a myriad of signs and symptoms, the most often diagnosed of which includes loss of the ability to supinate the forearm while still being able to extend it. Loss of forearm extension can occur when the radial nerve is injured in the axilla. Injury to the nerve in the arm does not significantly impact the triceps and the anconeus, therefore the ability to extend the forearm remains intact [6]. Motor deficits include loss of mobility in the brachioradialis and supinator muscle, which supinate the forearm, as well as loss of mobility in the extensor carpi radialis longus and brevis, which extends the wrist. An inability to extend the fingers at the metacarpophalangeal joints may also result.

Extension of the interphalangeal joints remains intact as the lumbricals and interosseous are innervated by the ulnar nerve [7]. The sensory deficits include loss of sensation in the posterior forearm, dorsum of the hand and lateral three and a half fingers. Sensation in the posterior arm remains intact as it is innervated by the radial nerve before it reaches the diaphysis of the humerus [8]. These signs are often accompanied with pain, tingling, and numbness [2, 9]. Radiography is essential to look for a fracture or dislocation and electromyography examinations are crucial to assess the recovery or persistence of the lesion $[10,11]$. All Radial nerve palsies associated with open wounds should be explored surgically. If the nerve has been sharply transected, but there is adequate nerve length and minimal soft-tissue injury, then it should be repaired 
primarily. A primary nerve repair should be performed without tension. Nerve grafting is indicated if the nerve defect is large or there is significant tension on the repair [2, 10, 12]. Patient follow-up is important and electromyography examinations should not be done too early (6 months for the radial nerve). There are several important factors that influence nerve recovery such as age, level of injury, length of defect, associated injuries, and interval to surgery [10, 13-18]. Most authors agree that tendon transfers provide good results if the nerve reconstruction fails. Sunderland recommended a tendon transfer if there were no signs of recovery within 1 year $[2,3,19]$.

\section{Conclusion}

The incidence of penetrating trauma in Morocco are rising and witness of the violence in the big cities of the World. Initial clinical evaluation is important, all penetrating trauma need a surgical exploration: a puncture wound can be enough to damage a nerve, tendon, artery. According to the literature, primary nerve repair provides excellent results, ranging between 78 and 90 percent, and avoid to the victim the handicap of a radial palsy.

Conflict of interest: All authors report no conflicts of interest.

Consent: The patient gives us informed consent for publication

\section{Sources of Funding}

All authors disclose that this manuscript didn't received no specific grant from any funding agency.

Ethical Approval: This is a case report and the patient give us informed consent for publication.

\section{REFERENCE}

1. Agha RA, Fowler AJ, Saetta A, Barai I, Rajmohan S, Orgill DP, for the SCARE Group. The SCARE Statement: Consensus-based surgical case report guidelines. International Journal of Surgery. 2016; 34:180-186.

2. Barton N. Radial nerve lesions. Hand. 1973; 5(3):200-208.

3. James B. Current approach to radial nerve paralysis. Plast Reconstr Surg. 2002; 110(4):1099-1112.

4. Richmond D. Lipoma causing a posterior interosseuous nerve lesion. J Bone Joint Surg Br.
1953; 35-B (1): 83.

5. Moon N, Marmor L. Perosteal lipoma of the proximal part of the radius. J bone Joint Surg Am. 1964; 46(3): 608-614.

6. Namerow NS, Campion DS, Bluestone R, Cracchiolo A. Peripheral nerve entrapments. West J Med. 1977; 127:299-313.

7. Bumbasirevic M, Palibrk T, Lesic A, Atkinson HD. Radial nerve palsy. EFORT open reviews. 2016 Aug;1(8):286-94.

8. DeFranco MJ, Lawton JN. Radial nerve injuries associated with humeral fractures. J Hand Surg Am. 2006; 31:655-663.

9. Vural M, Arslantas A. Delayed radial nerve palsy due to entrapment of the nerve in the callus of a distal third humerus fracture. Turk Neurosurg. 2008; 18(2):194-6.

10. Durandeau A, Fabre T. Lesions traumatiques des nerfs périphériques. Encycl Méd Chir (Éditions Scientifiques et Médicales Elsevier), Appareil locomoteur, 2000, 15-003-A-10: 1-12.

11. Seror P. Examen électromyographique du membre supérieur: Technique, intérêt et limites. Tubiana T éd. Traité de chirurgie de la main. Paris: Masson, 1991: 19-47.

12. Bourrel P, Ferro RM, Lorthior JM. Résultats cliniques comparés des sutures nerveuses « mixtes » épipérineurales et des sutures névrilemmatiques: à propos d'une série de 190 cas de plaies des nerfs de la main. Sem Hôp Pars. 1981; 57:2015-2023.

13. Mailander P, Berger A, Schaller E, Ruhe K. Results of primary nerve repair in the upper extremity. Microsurgery. 1989; 10(2):147.

14. Moberg E. Criticism and study of methods of examining sensibility in the hand. Neurology. 1962; $12(1): 8$.

15. Dellon A. The moving tow-point discrimination test: Clinical evaluation of the quickly adapting fiber receptor system. J Hand Surg Am. 1978; 3(5):474.

16. Millesi $H$. Progress in peripheral nerve reconstruction. World J Surg. 1990; 14(6):733747.

17. Bevin A. Early tendon transfer for radial nerve transection. Hand. 1976; 8(2):134-136

18. Lilla J, Pherlps D, Boswick J. Microsurgical repair of peripheral nerve injuries in the upper extremity. Ann Plast Surg. 1979; 2(1) :24-31.

19. Sunderland S. Traumatic injuries of the peripheral nerve: Simple compression of the radial nerve. Brain. 1945; 68(1):56-72. 